\title{
Energy Management System Control for a Hybrid Non-conventional Energy Sources using Hysteresis Switching Algorithm
}

\author{
S. Devi ${ }^{1}$, R. Saravanapriyan ${ }^{2}$ \\ Associate Professor, Dept. of EEE, K.S.Rangasamy College of Technology, Tiruchengode, Tamilnadu, \\ India $^{1}$ \\ PG Student [PSE], Dept. of EEE, K.S.Rangasamy College of Technology, Tiruchengode, Tamilnadu, India ${ }^{2}$
}

\begin{abstract}
Renewable energy sources play an important role in electrical energy generation. The drawbacks of Renewable energy sources have been overcome by the use of hybrid power generating unit. A typical hybrid renewable energy system (HRES) combines several renewable energy sources such as wind turbine (WT) and photovoltaic (PV) panels as primary energy sources and an energy storage system (ESS) based on fuel cell and battery. All of the energy sources are connected together to a central dc bus by means of power converters. This paper includes a supervisory control called hysteresis switching algorithm which determines the power that must be generated by/stored in the fuel cell and battery, taking into account the control demand by the grid, the offered power, the hydrogen reservoir point and the state-of-charge (SOC) of the battery. The proposed EMS is compared with classical EMS composed of state based supervisory control system based on states and inverter control system based on PI controller. Dynamic simulation results of the proposed EMS demonstrate the better performance than the classical EMS.
\end{abstract}

KEYWORDS: Hysteresis, Energy management system, Energy storage system, Renewable power sources, Mixture system.

\section{I.INTRODUCTION}

A typical HRES configuration combines several renewable energy sources, such as wind turbine (WT) and photovoltaic (PV) panels, with ESS. The renewable sources are used as primary energy sources, which are generating whenever there is wind or solar radiation. However, because the sun irradiance and the wind speed are uncontrollable parameters, a support energy source is needed to increase the degree of controllability and operability of the HRES. Traditionally, this function is performed by an ESS such as battery and hydrogen system (i.e., FC, electrolyzer and hydrogen storage tank). These ESS are considered to be an effective solution to balance the generation and demand supporting the renewable energy deficit when necessary, and storing the primary energy excess when possible. All renewable sources and ESS are connected together to a central dc bus by means of power converters. These converters are designed to deliver energy from the energy sources, ensuring stable, sustainable and reliable operation. In gridconnected mode, $\mathrm{dc}-\mathrm{dc}$ and ac-dc power converters interface the renewable sources and ESS to a dc bus, while dc-ac voltage source inverters are in charge of delivering the active and reactive power to the grid.

HRES presents two-level control architecture. In the highest level, the supervisory control system is responsible for determining the reference power that must be generated by/stored in the ESS. The lowest level is in charge of controlling the converters associated with the renewable sources and ESS, so that the energy sources work as required by the supervisory control system. Most of the studies about HRES control architectures consider standalone operation in isolated sites due to the advances in renewable energy technologies and power electronic converters, which are used to convert the unregulated power generated from the renewable sources into useful power at the load end. Classical and intelligent control techniques have been applied to the control system of stand-alone HRES. Classical control techniques (i.e., based on state machine controllers or PI controllers) require exact mathematical model of the system and are very sensitive to parameter variations. Intelligent control techniques such as artificial neural networks, fuzzy 


\section{2 \\ International Journal of Advanced Research in Electrical, Electronics and Instrumentation Engineering}

ISSN (Print) : $2320-3765$

ISSN (Online): 2278 - 8875

(An ISO 3297: 2007 Certified Organization)

\section{Vol. 4, Issue 2, February 2015}

logic, or neuro-fuzzy are more efficient and robust than classical techniques, since they do not require an exact model of the system and improve the dynamic behaviour of the system.

This paper presents a new hysteresis-based EMS for a HRES composed of renewable energies, hydrogen and battery, and an hysteresis-based control for the three-phase inverter, which connects the HRES to grid. The main novelties of this paper are: 1) the application of hysteresis to the supervisory control system of a grid-connected HRES in order to determine the power that must be generated by/stored in the ESS (hydrogen and battery), taking into account the control demand by the grid, the offered power, the hydrogen tank level and the battery SOC and 2) the application of hysteresis to the three-phase inverter in order to properly control the power delivery to grid by using the active and reactive power as control variables. It is organized as follows. Section II describes the grid-connected hybrid system under study. Section III describes the classical EMS used to evaluate the performance of the Hysteresis based EMS. Simulation results are presented in section IV. Finally, Section V establishes the conclusions derived from this work.

\section{II.GRID-CONNECTED HYBRID SYSTEM}

Fig. 1 shows the grid-connected hybrid system under study in this work, which is composed of WT and PV panels (renewable and primary energy sources) and hydrogen subsystem and battery (ESS). All of them use dc-dc power converters in order to connect them to a central dc bus. The whole system is connected to a grid by a three-phase inverter. In this system, the renewable sources are generating whenever there is wind or solar radiation. When possible, renewable energy is stored in the battery and/or in the form of hydrogen by using the electrolyzer, and this stored energy is recovered to support the renewable production when necessary.

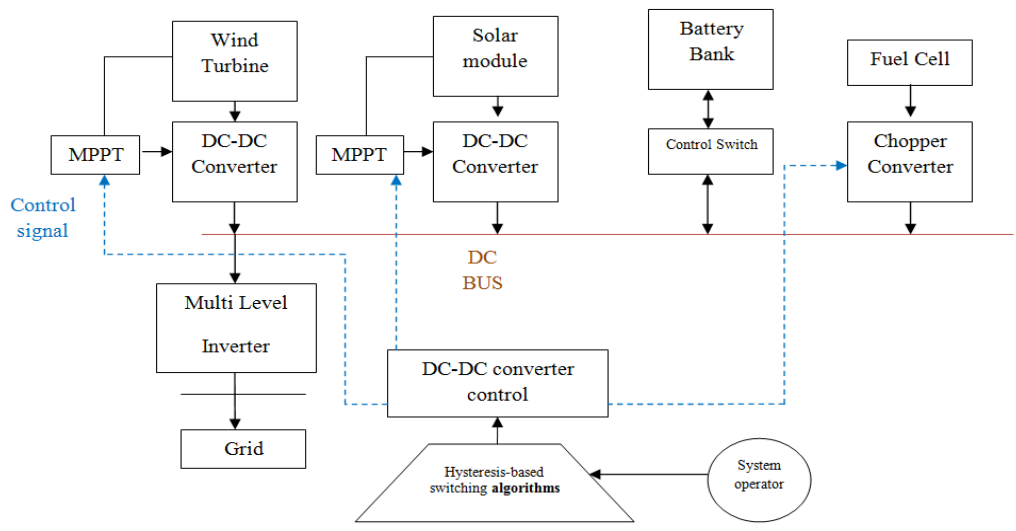

Fig. 1 Grid-connected hybrid system

A dynamic model of this grid-connected hybrid system is implemented in a MATLAB/Simulink environment, as described below.

\section{A. Wind Turbine}

The WT presents a rated power of $1.5 \mathrm{~kW}$. It presents a two blade turbine coupled to a three-phase permanent magnet synchronous generator (PMSG). This WT is represented by a model with the following subsystems: turbine and generation system. The turbine model expresses the mechanical power extracted from the wind, which is a function of the wind speed and the blade tip speed ratio, as defined by the actuator disk theory. The generation system is composed of a three-phase PMSG, ac-dc converter, and dc-dc converter, which are represented by models included in Sim Power Systems [1]. The electrical and mechanical parts of the PMSG are represented by a second order state-space model. The ac- $d c$ and $\mathrm{dc}-\mathrm{dc}$ converters are modeled by average-value equivalent models. The dc-dc power converter, which connects the WT to the hybrid system dc bus, is controlled by a torque reference-based maximum power point tracking (MPPT) control in order to extract the maximum available power from the WT. This MPPT control maintains the operating point of the WT on its maximum power coefficient for any wind speeds in the below-rated wind speed region, modifying the duty cycle of the WT dc-dc converter, which produces a variation of its rotational speed. 


\section{2 \\ International Journal of Advanced Research in Electrical, Electronics and Instrumentation Engineering}

ISSN (Print) : $2320-3765$

ISSN (Online): 2278 - 8875

(An ISO 3297: 2007 Certified Organization)

\section{Vol. 4, Issue 2, February 2015}

Furthermore, the WT generation system incorporates a braking resistor at the dc bus, in which the power excess with above nominal winds is dissipated to assure WT rated power.

\section{B. PV Panels}

The PV system presents nine $0.180-\mathrm{kW}$ PV panels, with a total rating of 1.6kW.Asingle-diodemodel, which is composed of a current source and a parallel diode (representing the ideal PV cell) with two resistances (series and parallel resistances), is used to represent each PV panel. This model presents suitable accuracy [1], and the parameters are easy to find in the commercial datasheets [7], which makes it perfect for the simulation of PV devices with power converters. A dc-dc power converter controlled by a MPPT controller adapts the PV output voltage to the dc bus voltage. The MPPT controller generates the duty cycle of the PV converter to move the PV voltage to the voltage that corresponds to the maximum power point (MPP). In this work, the MPP voltage is defined as proportional to the PV open-circuit voltage [11]. Thus, a fractional open-circuit voltage algorithm is used as MPPT algorithm to generate the duty cycle of the controller due to its simplicity.

\section{Hydrogen Subsystem}

The hydrogen subsystem is composed of 0.48-kWPEM electrolyzer, 2280-liter hydrogen tank, and 1.2-kW PEM FC. PEM electrolyzer and PEM FC are highly efficient units that are suitable for autonomous and distribution operation [5]. The PEM electrolyzer uses electrical energy to produce hydrogen from water. It is modeled by a resistance, in which the power needed to produce hydrogen is consumed. Faraday's law is used to calculate the hydrogen produced depending on the electrical current in the resistance [4]. The hydrogen produced by the electrolyzer is stored in the hydrogen tank. In the hydrogen tank model, the hydrogen available in the tank is obtained from the rate of incoming and outgoing hydrogen, taking into account the ideal gas equation [2]. The PEM FC uses the hydrogen available in the tank in order to produce electrical energy. It is modelled by a reduced model of the complete model detailed in [10].

The validity of the reduced model was demonstrated in [8], where both the reduced and complete models were compared, showing similar responses, but with a considerable reduction of the computational time for the first one. Several control strategies for FC vehicles [2]-[5] were evaluated by using this reduced model. In this reduced model, the FC voltage depends on the cell voltage and number of cells [1], [5]. The cell voltage is determined as a function of the current density, temperature, and water, and hydrogen and oxygen partial pressures. The compressor, which controls the air flow in the cathode to keep constant the oxygen excess ratio, is represented by a first-order system. Finally, an ideal air cooler and humidifier are considered in the FC model [4].

\section{Batteries}

The hybrid system uses a 14.48-kWh lead-acid battery. This type of battery is usually the least expensive storage battery for any application, while still providing good performance and life characteristics [4]. This battery is modelled by a conflict in series with a variable voltage source [5].

\section{E. DC-DC Converters}

Each energy source of the hybrid system provides a variable voltage, which depends on the current demand, at different ranges. Therefore, it uses a pulse-width modulated (PWM) dc-dc converter [6] to transfer the output power to the central dc bus. The output voltage of the WT rectifier is higher than the dc bus voltage. Thus, the WT plus rectifier system is connected to the dc bus by using a buck-type unidirectional converter. The connection of PV, FC, and electrolyzer to the dc bus is performed by using boost-type unidirectional converters. The PV and FC converters transfer power from the source to the dc bus, since both sources terminal voltages are lower than the dc bus voltage. The electrolyzer converter transfers power from the dc bus to the electrolyzer, whose terminal voltage is higher than the $\mathrm{dc}$ bus voltage. The battery uses a bidirectional converter, which allows the power flow from the battery to the dc bus (boost-type) and vice versa (buck-type). Each dc-dc converter is modeled by using the two-quadrant chopper model included in SimPowerSystems [9]. In this model, the chopper is represented by a simplified version of the converter containing an average-value equivalent model. 


\section{9 \\ ISSN (Print) : $2320-3765$ \\ ISSN (Online): 2278 - 8875 \\ International Journal of Advanced Research in Electrical, Electronics and Instrumentation Engineering

\author{
(An ISO 3297: 2007 Certified Organization)
}

\section{Vol. 4, Issue 2, February 2015}

\section{F. Inverter}

A three-phase IGBT inverter connects the dc bus of the hybrid system to grid. This inverter is represented by the model developed in [3]. In this model, the snubber capacitor is eliminated, so that only the snubber resistance is taken into account. Furthermore, the forward voltages of the IGBTs and diodes are considered null. The inverter is PWM to produce the three-phase $50-\mathrm{Hz}$ sinusoidal voltage. It uses hysteresis switching and controls the active and reactive power, as will be shown below.

\section{III.CLASSICAL ENERGY MANAGEMENT SYSTEM OF THE HYBRID SYSTEM}

Here, the classical EMS used to test the performance of the proposed Hysteresis control system is described. The classical EMS is composed of state-based supervisory control system based on states and inverter control system based on PI controllers.

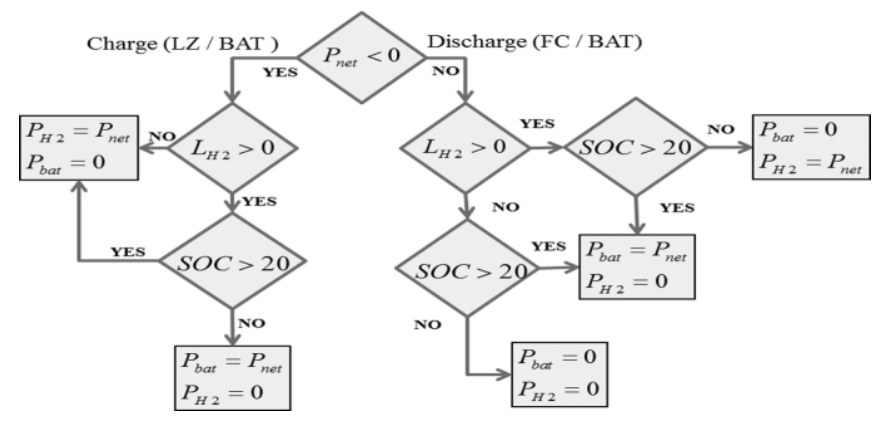

Fig. 2 Scheme of the supervisory control system based on states

The supervisory control system uses the control scheme shown in Fig. 2 in order to determine the power generated by/stored in the hydrogen and battery, taking into account the power demanded by the grid, the available power, the hydrogen tank level and the battery SOC.

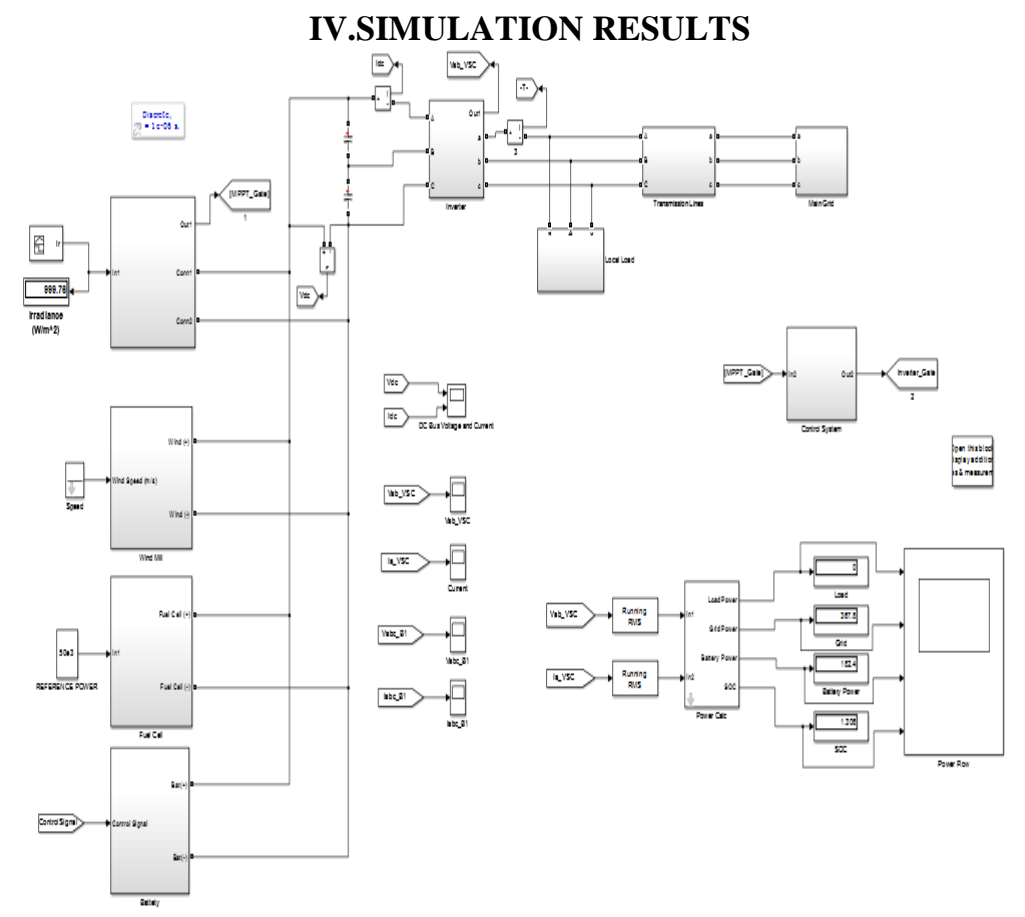

Fig. 3 Simulation Model in MATLAB/Simulink 


\title{
9 \\ International Journal of Advanced Research in Electrical, Electronics and Instrumentation Engineering
}

\author{
(An ISO 3297: 2007 Certified Organization)
}

ISSN (Print) : $2320-3765$

ISSN (Online): 2278 - 8875

\section{Vol. 4, Issue 2, February 2015}

Fig. 3 presents the power demanded by the network and the power of each energy source during 20 s. As mentioned previously, the renewable sources are generating the maximum available power. During the first $10 \mathrm{~s}$, the renewable power (PV and WT power) is higher than the power demanded by the grid. In this case, the power excess is stored in the battery and used in the electrolyzer to produce hydrogen. From the second $10 \mathrm{~s}$, the power demanded by the grid increases, and it becomes higher than the renewable power. Then, the FC and battery generate extra power to satisfy the demanded power.

Table I Presents the results (i.e., battery, hydrogen system, and hybrid system efficiencies and the energy injected into grid) obtained by each control during the first simulation. Analyzing the results, it can be concluded that the Hysteresis control achieves higher battery and hybrid system efficiencies, and it is capable of injecting more energy into grid than the classical control. It shows in detail the dynamic behaviour of the supervisory controls and inverter control systems.

The implemented EMS is based on a predictive controller, which generates the FC and battery reference currents to provide the power demanded by the tramway, meeting the battery and SC SOC constrains (i.e., keeping their SOC between a specific range) and ordering the operation of the braking resistor, when necessary, during regenerative braking[4].

Table I. Summary Of Results Obtained In The Simulation

\begin{tabular}{|l|l|}
\hline Parameters & Efficiency \\
\hline PV panels (\%) & 95 \\
\hline Wind Turbine, $\eta \mathrm{HS}(\%)$ & 66 \\
\hline Fuel cell, $\eta \mathrm{H} 2(\%)$ & 38 \\
\hline Battery, $\eta$ bat (\%) & 75 \\
\hline Energy injected, Einvinj (kWh) & $5280 \mathrm{kWh}$ \\
\hline
\end{tabular}

\section{A .Charging condition}

Fig. 4 presents load is off. The power flow through grid and battery. Here the battery is charging mode.

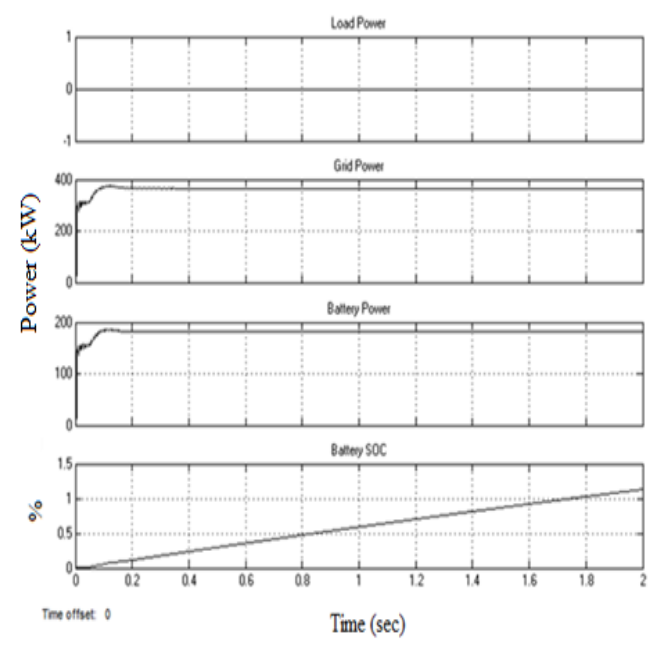

Fig. 4 Power flow in Load, Grid, Battery Power and State of Charge 


\section{International Journal of Advanced Research in Electrical, Electronics and Instrumentation Engineering}

(An ISO 3297: 2007 Certified Organization)

Vol. 4, Issue 2, February 2015

\section{B.Discharging situation}

Fig. 5 presents load is on. The power flow through load only. Here the battery is discharging mode.

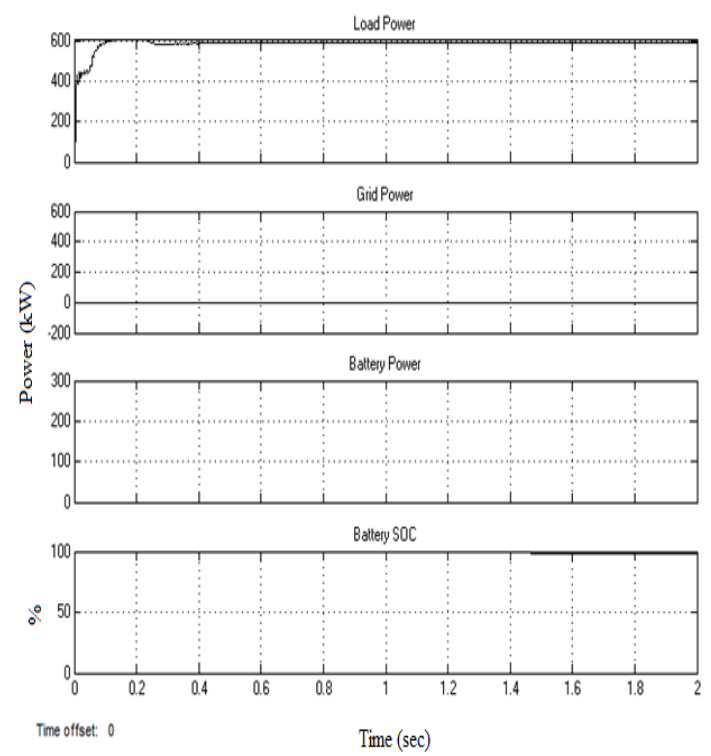

Fig. 5 Power flow in Load, Grid, Battery Power and State of Charge

\section{V.CONCLUSION}

The renewable energy sources operate at the Maximum Power Point, independently of the Energy Management System (EMS). Therefore, the EMS is responsible for managing the operation of the ESS (battery and hydrogen system), taking into account the power demanded by the grid, the available renewable power, and the available ESS power (battery SOC and hydrogen tank level). Once determined which ESS has to absorb/generate the power excess/deficit, the appropriate control of the dc-dc converter associated to the battery and hydrogen system allows the ESS to achieve the operation required by the EMS, maintaining constant the dc bus voltage. On the other hand, in coordination with the EMS, the three phase inverter is controlled by a Hysteresis-based controller in order to regulate the active and reactive power that the hybrid system is required to deliver with the grid.

\section{REFERENCES}

1. Chunhua Liu, Xiaodong Zhang, "An Efficient Wind-Photovoltaic Hybrid Generation System using Doubly Excited Permanent-Magnet Brushless Machine”, IEEE Trans. Ind. Electron., vol. 57, no. 3, pp.831-839, 2013.

2. F. Kennel, D. Görges, and S. Liu, "Energy management for smart grids with electric vehicles based on hierarchical MPC," IEEE Trans. Ind. Inf., vol. 9, no. 3, pp. 1528-1537, Aug. 2013.

3. F.González-Espín, I. Patrao, E. Figueres, and G.Garcerá, "An adaptive digital control technique for improved performance of grid connected inverters," IEEE Trans. Ind. Inf., vol. 9, no. 2, pp. 708-718, May 2013.

4. J. P. Torreglosa, P. García, L.M. Fernández, and F. Jurado, "Predictive control for the energy management of a fuel cell-battery-super capacitor tramway," IEEE Trans. Ind. Inf., vol. 10, no. 1, pp. 276-285, Feb. 2014.

5. L. Valverde, F. Rosa, and C. Bordons, "Design, planning and management of a hydrogen-based microgrid," IEEE Trans. Ind. Inf., vol. 9, no. 3, pp. 1398-1404, Aug. 2013.

6. M. P. Kazmierkowski, M. Jasinski, and G.Wrona, "DSP-based control of grid-connected power converters operating under grid distortions," IEEE Trans. Ind. Inf., vol. 7, no. 2, pp. 204-2011, May 2011.

7. M. Singh and A. Chandra, "Real-time implementation of ANFIS control for renewable interfacing inverter in 3P4W distribution network," IEEE Trans. Ind. Electron., vol. 60, no. 1, pp. 121-128, Jan. 2013

8. P. Siano, C. Cecati, H. Yu, and J. Kolbusz, "Real time operation of smart grids via FCN networks and optimal power flow," IEEE Trans. Ind. Inf., vol. 8, no. 4, pp. 944-952, Nov. 2012.

9. S. Dasgupta, S. N. Mohan, S. K. Sahoo, and S. K. Panda, “A plug and play operational approach for implementation of an autonomous micro- grid system," IEEE Trans. Ind. Inf., vol. 8, no. 3, pp. 615-629, Aug. 2012.

10. S. N. Bhaskara and B. H. Chowdhury, "Microgrids - A review of modeling, control, protection, simulation and future potential," in Proc. IEEE Power and Energy Soc. Gen. Meeting, 2012, pp. 1-7.

11. Z. Nie, X. Xiao, R. McMahon, P. Clifton, Y. Wu, and S. Shao, "Emulation and control methods for direct drive linear wave energy converters," IEEE Trans. Ind. Inf., vol. 9, no. 2, pp. 790-798, May 2013. 